\title{
Editorial
}

\section{Ulam's Type Stability and Fixed Points Methods}

\author{
Janusz Brzdęk, ${ }^{1}$ Liviu Cădariu, ${ }^{2}$ Krzysztof Ciepliński, ${ }^{1,3}$ \\ Ajda Fošner, ${ }^{4}$ Zbigniew Leśniak, ${ }^{1}$ and Bing $\mathrm{Xu}^{5}$ \\ ${ }^{1}$ Department of Mathematics, Pedagogical University, Podchorażych 2, 30-084 Krakow, Poland \\ ${ }^{2}$ Department of Mathematics, Politehnica University of Timişoara, Piața Victoriei No. 2, 300006 Timişoara, Romania \\ ${ }^{3}$ Faculty of Applied Mathematics, AGH University of Science and Technology, Mickiewicza 30, 30-059 Krakow, Poland \\ ${ }^{4}$ Faculty of Management, University of Primorska, Cankarjeva 5, 6104 Koper, Slovenia \\ ${ }^{5}$ Department of Mathematics, Sichuan University, Chengdu, Sichuan 610064, China
}

Correspondence should be addressed to Janusz Brzdęk; jbrzdek@up.krakow.pl

Received 21 August 2014; Accepted 21 August 2014; Published 3 September 2014

Copyright ( 2014 Janusz Brzdęk et al. This is an open access article distributed under the Creative Commons Attribution License, which permits unrestricted use, distribution, and reproduction in any medium, provided the original work is properly cited.

Considering the issue of stability of functional equations we follow a question raised in 1940 by S. M. Ulam concerning approximate group homomorphisms. The first partial answer to this question was given in a paper published in 1941 by D. H. Hyers.

The method used by Hyers (quite often called the direct method) has been successfully applied for study of the stability of large variety of equations. Apart from it, there are also several other efficient approaches to the Ulam type stability, using different tools. The second most popular technique of proving such stability results for (not necessarily functional) equations is the fixed point method. It was used for the first time in 1991 by J. A. Baker who applied a variant of Banach's fixed point theorem to obtain a stability outcome for a functional equation in a single variable. At present, numerous authors follow Radu's approach and make use of a theorem of Diaz and Margolis.

The Hyers-Ulam stability (or more generally, Ulam's type stability) theory is the subject of many papers as well as talks presented at various conferences. On June 2-6, 2014, the Department of Mathematics of the Pedagogical University of Cracow organized the Conference on Ulam's Type Stability, the first meeting dedicated in its entirety to this topic. Its 60 participants came from 16 countries.

This volume includes 10 research articles (a survey and 9 regular papers) containing the latest achievements in that type of stability and its connections to the fixed point theory. They have been written by 22 authors from 5 countries.
As usual, several contributors use in their studies the direct method.

Most of the papers deal with the stability of functional equations, and thus Pexider, quadratic, cubic, quadratic reciprocal, quadratic-additive type, quadratic-quartic type, and exponential with an involution equations are considered. These investigations concern classical normed spaces, nonArchimedean normed spaces, and random normed spaces.

Moreover, the volume provides some results on the stability of the differentiation operator on the Hilbert spaces of entire functions and on the stability and hyperstability of the Lie triple homomorphisms and derivations associated with a Cauchy-Jensen additive equation on normed Lie triple systems. There is also a paper on the convergence of sequences of fixed points (of some sequences of contraction mappings) in G-complete fuzzy metric spaces.

Finally, the volume contains a survey discussing applications of different fixed point theorems to the theory of stability of functional equations and the stability of the fixed point equation and its generalizations.

$$
\begin{array}{r}
\text { Janusz Brzdęk } \\
\text { Liviu Cădariu } \\
\text { Krzysztof Ciepliński } \\
\text { Ajda Fošner } \\
\text { Zbigniew Leśniak } \\
\text { BingXu }
\end{array}
$$




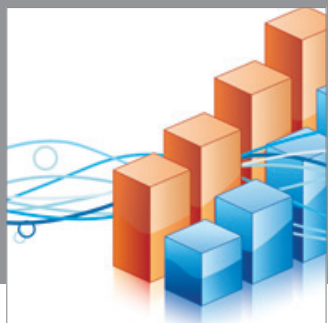

Advances in

Operations Research

mansans

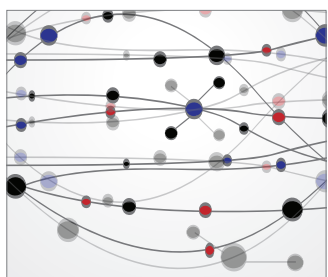

The Scientific World Journal
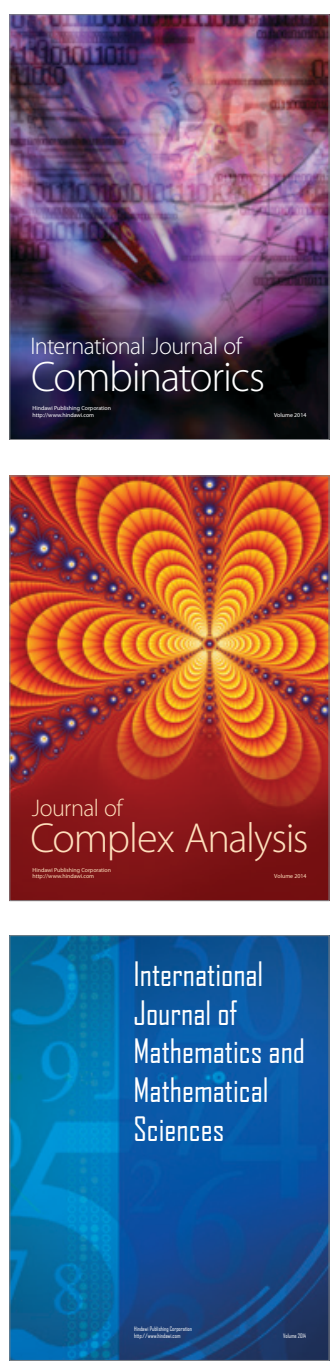
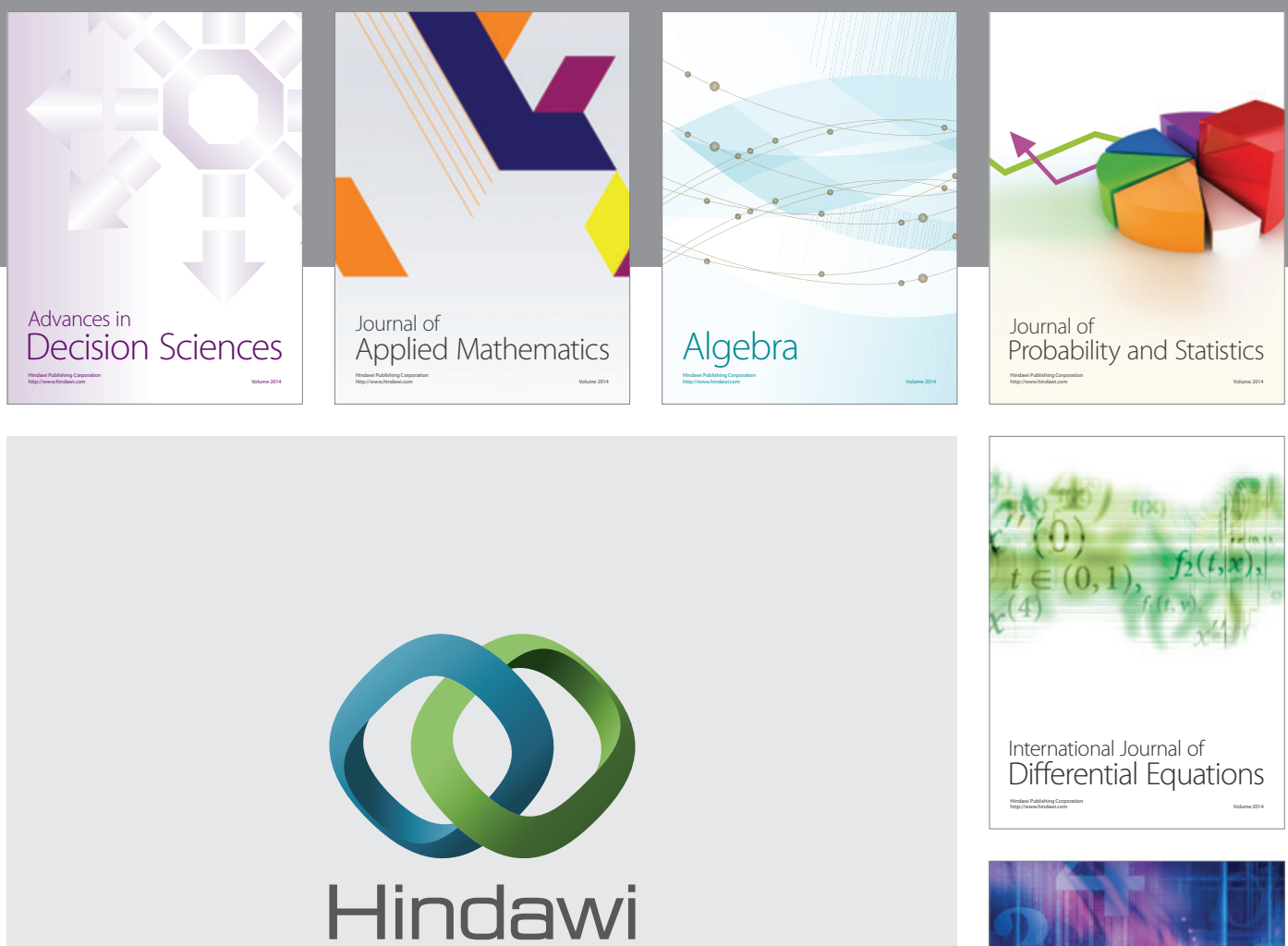

Submit your manuscripts at http://www.hindawi.com
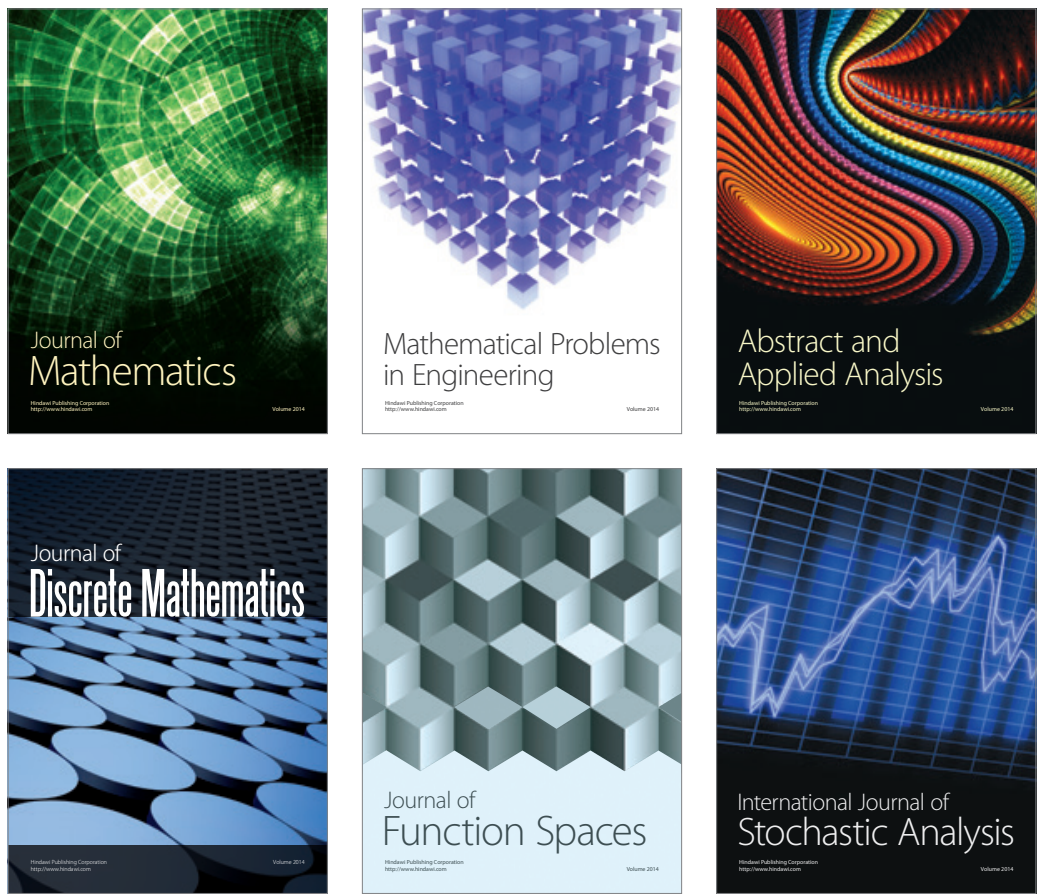

Journal of

Function Spaces

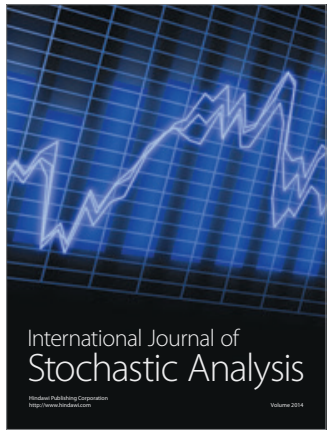

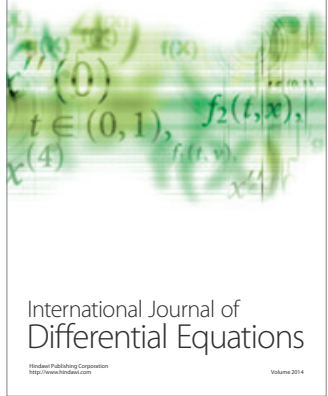
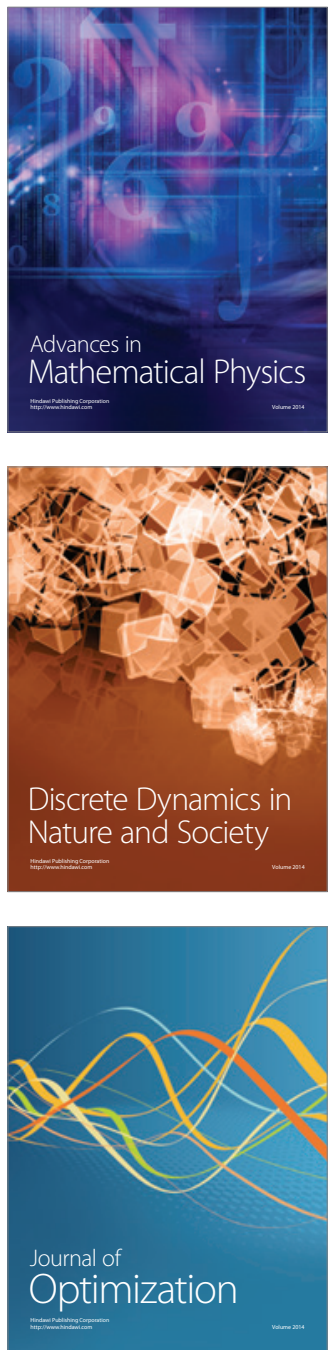